\title{
Body weight and weight gain related to pulmonary function decline in adults: a six year follow up study
}

\author{
Y Chen, S L Horne, J A Dosman
}

\begin{abstract}
Background-Obesity increases the risk of cardiovascular disease, hypertension, diabetes, digestive diseases, and some cancers. Several studies have shown that excess weight or weight gain is related to pulmonary dysfunction, but this issue needs to be further clarified.
\end{abstract}

Methods-The analysis was based on data of the Humboldt cohort study which was conducted in the town of Humboldt, Saskatchewan, Canada. The baseline survey in 1977 included 1202 adults, comprising $94 \%$ of all residents aged 25-59 years. Of these, 709 (59\%) were followed up in 1983. Pulmonary function (forced vital capacity (FVC), forced expiratory volume in one second $\left(F_{E V}\right)$ and maximal mid expiratory flow rate (MMFR)) and weight were measured in both surveys. Weight gain was determined by subtracting weight at baseline from weight at follow up. A residual analysis was used to examine the relationship between body mass index (BMI) at baseline, weight gain, and pulmonary function decline.

Results-Both BMI at baseline and weight gain were significantly related to pulmonary function at follow up. The effect of weight gain during the study period, however, was more prominent. The results showed that both mean residual FVC and $F E V_{1}$ were highest in the group that gained $<1.0 \mathrm{~kg}$, lowest in the group that gained $\geqslant 4.0 \mathrm{~kg}$, and intermediate in the group that gained 1.0-3.9 $\mathrm{kg}$ in both men and women after taking age, BMI at baseline, and smoking into account. The effect of weight gain on pulmonary function was greater in men than in women. Multiple regression analysis showed that each kilogram of weight gain was associated with an excess loss of $26 \mathrm{ml}$ in FVC and $23 \mathrm{ml}$ in $\mathrm{FEV}_{1}$ in men, and $14 \mathrm{ml}$ and $9 \mathrm{ml}$ respectively in women.

Conclusions-Weight gain is significantly related to lung dysfunction. The effect of weight gain on pulmonary function is greater in men than in women.

(Thorax 1993;48:375-380)
The relationship between obesity or excess weight and health and longevity has been receiving increasing attention. ${ }^{12}$ Numerous epidemiological studies have shown that obesity might increase the risk of cardiovascular disease, hypertension, diabetes, and cancer, as well as other diseases including arthritis, gout, kidney stones, and gallbladder disease. ${ }^{1}$ A number of clinical studies ${ }^{3-13}$ have described the effects of obesity on lung function test variables including functional residual capacity and expiratory reserve volume; however, the studies on the relationship between obesity and airways function have given inconsistent results.

Body weight and weight gain as risk factors for pulmonary dysfunction have not been well documented by population based studies. In a cross sectional study of data from 3046 children and adults (seven years and over), Schoenberg et $a l^{14}$ found that pulmonary function initially increased as weight increased and then decreased as weight continued to increase. They considered that the increase of pulmonary function with weight may reflect increasing muscle force, and the decrease with further weight gain may be due to obesity which limits the mobility of the thoracic cage. ${ }^{14}$ Two other cross sectional studies gave similar results, ${ }^{15} 16$ and another found that weight gain was linearly related to decline in FVC and $\mathrm{FEV}_{1} .{ }^{17}$ Two longitudinal studies conducted in men found that weight gain was significantly related to losses in FVC. ${ }^{18} 19$ In a cross sectional study of steelworkers, however, Nemery et al ${ }^{20}$ reported that $\mathrm{BMI}$ and $\mathrm{FEV}_{1} / \mathrm{FVC}$ showed a positive significant correlation in smokers but not in non-smokers. Whether body weight and weight gain are related to airways dysfunction needs to be further clarified.

This cohort analysis examines the effects of body weight at baseline and subsequent weight gain on decline of pulmonary function test variables in both men and women.

Methods

SUBJECTS

The study was conducted in the town of Humboldt, Saskatchewan. In the baseline study in 1977, 1202 adults aged 25-59 years
Returned to authors

14 September 1992

Revised version received

1992

Accepted 17 November 1992 
representing $94 \%$ of the target population participated $^{21} ; 709$ individuals from the 1977 baseline survey were followed up in 1983. A comparison of these who stayed with those who dropped out showed that the dropouts had a higher proportion of smokers and a lower mean age than the stayers. There were no significant differences in diștribution of sex, mean height, or weight.

PULMONARY FUNCTION TESTS

In the baseline survey in 1977 the forced expired manouevre was performed with a Godart 8 litre water spirometer until three acceptable tracings, (FVC within 5\% of the maximum value), to a maximum of five attempts, were obtained. The best FVC and $\mathrm{FEV}_{1}$ and $\mathrm{MMFR}$ values which came from the tracing with the largest FVC were used in the analysis. ${ }^{21}$ In the follow up survey in 1983, FVC, $\mathrm{FEV}_{1}$ and MMFR were also measured. ${ }^{22}$ Three subjects who had no pulmonary function measurements at the baseline or follow up surveys were not included in the analysis.

\section{WEIGHT AND HEIGHT MEASUREMENTS}

Weight (kg) was measured on a spring scale without shoes and in normal indoor clothing during both baseline and follow up surveys. Height (cm) was recorded without shoes. BMI was calculated from the equation: BMI = weight $(\mathrm{kg}) /$ height $(\mathrm{m})^{2}$. Weight gain was determined by subtracting weight at baseline from weight at follow up. Individuals with a weight gain of $30 \mathrm{~kg}$ or more were considered to be outliers, and three such subjects (one man and two women) were excluded from the analysis.

SMOKING AS A COVARIATE

Smoking history was determined at the baseline and follow up interviews. A "never smoker", or a "continuing ex-smoker" or a "continuing smoker" was defined as a person who was a non-smoker, an ex-smoker or a smoker at both baseline and follow up interviews, and whose smoking state had not changed in the interim. A "new ex-smoker" was defined as a person who was a smoker at baseline but an ex-smoker at follow up. A person who was a non-smoker at baseline and a smoker or an ex-smoker in follow up was defined as an "other smoker."

\section{STATISTICAL METHODS}

A stagewise (or residual) analysis was used in the analysis. ${ }^{23}$ Firstly the values of pulmonary function measurements from the follow up survey were regressed on the values from the baseline survey in men and women separately:

$$
\begin{aligned}
& \mathrm{PF}_{1983}=\mathrm{a}+\mathrm{b}\left(\mathrm{PF}_{1977}\right)+\mathrm{E}, \quad \text { or } \\
& \mathrm{E}=\mathrm{PF}_{1983}-\left[\mathrm{a}+\mathrm{b}\left(\mathrm{PF}_{1977}\right)\right],
\end{aligned}
$$

where $\mathrm{PF}_{1983}$ and $\mathrm{PF}_{1977}$ represent the measurement of either FVC, FEV $_{1}$, or MMFR from the follow up and baseline surveys respectively, $a$ is a constant, $b$ is the regres- sion coefficient, and $\mathrm{E}$ is the random error (residual) of pulmonary function measurement.

Secondly, analysis of covariance and multiple regression analysis ${ }^{24}$ were used to examine the relationships between the residual ( $r$ ) pulmonary function measurements (including rFVC, $\mathrm{rFEV}_{1}$, and rMMFR) and BMI at baseline and weight gain, after adjustment for confounding factors in men and women separately. One reason for using residual analysis is that it excludes past effects of weight change and other factors such as smoking and previous occupational exposures on pulmonary function decline during the study period. In addition, the variance of pulmonary function measurements at follow up was larger than at baseline. This approach was not influenced by this difference.

\section{Results}

Table 1 shows the mean values of age, height, weight, and BMI at baseline. The women were, on average, one year older than the men, but this was not significant $(F=1.984$, $\mathrm{p}=0 \cdot 160$ ). Mean BMI in men was significantly higher than in women, $27.5 \mathrm{~kg} / \mathrm{m}^{2} v$ $25.5 \mathrm{~kg} / \mathrm{m}^{2}(F=35.616, \mathrm{p}<0.001)$.

Mean rFVC, $\mathrm{rFEV}_{1}$, and rMMFR stratified by gender and BMI at baseline are given in table 2. The crude mean values of rFVC and $\mathrm{rFEV}$ in the $<24 \mathrm{~kg} / \mathrm{m}^{2}$ group appear to be higher than those in the 24.0-27.9 and $\geqslant 28.0 \mathrm{~kg} / \mathrm{m}^{2}$ groups in both men and women. Smoking, a most important risk factor of lung dysfunction, is also related to body weight. In this study the mean BMI at baseline was highest in ex-smokers, lowest in smokers, and intermediate in non-smokers (unpublished data). After adjustment for the covariates including age, weight gain, and smoking state by analysis of covariance, there were significant differences in $\mathrm{rFVC}$ and $\mathrm{rFEV}_{1}$ between $\mathrm{BMI}$ groups in men (table 2). The $\mathrm{rFEV}_{1}$ in men decreased significantly with increasing mean value of BMI at baseline. The adjusted mean $\mathrm{rFVC}$ in men was highest in the $<24 \mathrm{~kg} / \mathrm{m}^{2}$ group; however, the mean value was slightly higher in the $\geqslant 28.0$ $\mathrm{kg} / \mathrm{m}^{2}$ group than in the $24.0-27.9 \mathrm{~kg} / \mathrm{m}^{2}$ group, although they were very close. In women, both adjusted mean rFVC and $\mathrm{rFEV}_{1}$ were decreased with increasing $\mathrm{BMI}$ at baseline, but did not reach significance at $\alpha=0.05$ (table 2). Figure 1 illustrates the relationships between $\mathrm{rFVC}$ and $\mathrm{rFEV}_{1}$ and the value of baseline BMI in men and women after taking the covariates into account.

Table 1 Mean (SD) age, height, weight, and BMI of men and women at baseline

\begin{tabular}{lcc}
\hline & $\begin{array}{l}\text { Men } \\
(n=316)\end{array}$ & $\begin{array}{l}\text { Women } \\
(n=387)\end{array}$ \\
\hline Age (years) & $41 \cdot 5(9 \cdot 8)$ & $42.5(9 \cdot 9)$ \\
Height (cm) & $173.6(7 \cdot 4)$ & $161.9(6.0)$ \\
Weight $(\mathrm{kg})$ & $82 \cdot 8(12 \cdot 6)$ & $66.9(12 \cdot 8)$ \\
BMI $\left(\mathrm{kg} / \mathrm{m}^{2}\right)$ & $27.5(4 \cdot 1)$ & $25 \cdot 5(4 \cdot 7)$ \\
\hline
\end{tabular}

BMI-body mass index. 
Table 2 Mean (SD) residual pulmonary function test variables by BMI at baseline and gender, crude and adjusted for age, weight gain and smoking (analysis of covariance)

\begin{tabular}{|c|c|c|c|c|c|c|c|}
\hline \multirow[b]{2}{*}{$B M I\left(\mathrm{~kg} / \mathrm{m}^{2}\right)$} & \multirow[b]{2}{*}{$n$} & \multicolumn{2}{|l|}{$r F V C(l)$} & \multicolumn{2}{|l|}{$r F E V_{1}(\mathcal{l})$} & \multicolumn{2}{|l|}{$r M M F R(l / s)$} \\
\hline & & Crude & Adjusted & Crude & Adjusted & Crude & Adjusted \\
\hline \multicolumn{8}{|l|}{ Men } \\
\hline$<24 \cdot 0$ & 60 & $0.110(0.412)$ & $0 \cdot 131$ & $0.102(0.291)$ & $0 \cdot 117$ & $0.053(0.832)$ & 0.022 \\
\hline $24 \cdot 0-27 \cdot 9$ & 118 & $-0.609(0.413)$ & -0.050 & $-0.025(0.388)$ & -0.014 & $-0.104(1.002)$ & 0.134 \\
\hline$\geqslant 28 \cdot 0$ & 138 & $0.004(0.399)$ & -0.028 & $-0.023(0.277)$ & -0.049 & $-0.112(0.900)$ & -0.111 \\
\hline$F$ & & 3.507 & 4.537 & 3.623 & $6 \cdot 183$ & 1.855 & 2.493 \\
\hline $\mathbf{p}$ & & 0.031 & 0.011 & 0.028 & 0.002 & $0 \cdot 158$ & 0.084 \\
\hline \multicolumn{8}{|l|}{ Women } \\
\hline$<24 \cdot 0$ & 168 & $0.050(0.286)$ & 0.027 & $0.034(0.225)$ & 0.019 & $0.054(0.666)$ & -0.022 \\
\hline $24 \cdot 0-27 \cdot 9$ & 130 & $-0.007(0.294)$ & -0.006 & $0.001(0.240)$ & -0.003 & $0.007(0.641)$ & 0.017 \\
\hline$\geqslant 28 \cdot 0$ & 89 & $-0.084(0.338)$ & -0.061 & $-0.066(0.244)$ & -0.052 & $-0.112(0.556)$ & -0.066 \\
\hline$F$ & & $5 \cdot 776$ & $2 \cdot 635$ & $5 \cdot 259$ & $2 \cdot 824$ & 2.000 & 0.521 \\
\hline $\mathrm{p}$ & & 0.003 & 0.073 & 0.006 & 0.061 & $0 \cdot 137$ & 0.594 \\
\hline
\end{tabular}

BMI-body mass index; $r F V C$ - residual forced vital capacity; $\mathrm{rFEV}_{1}$-residual forced expired volume in one second; rMMFR-residual maximum mid expiratory flow rate.

Figure 1 Relationship between residual pulmonary function measurements and BMI at baseline in men and women (adjusted for age, weight gain, and smoking).

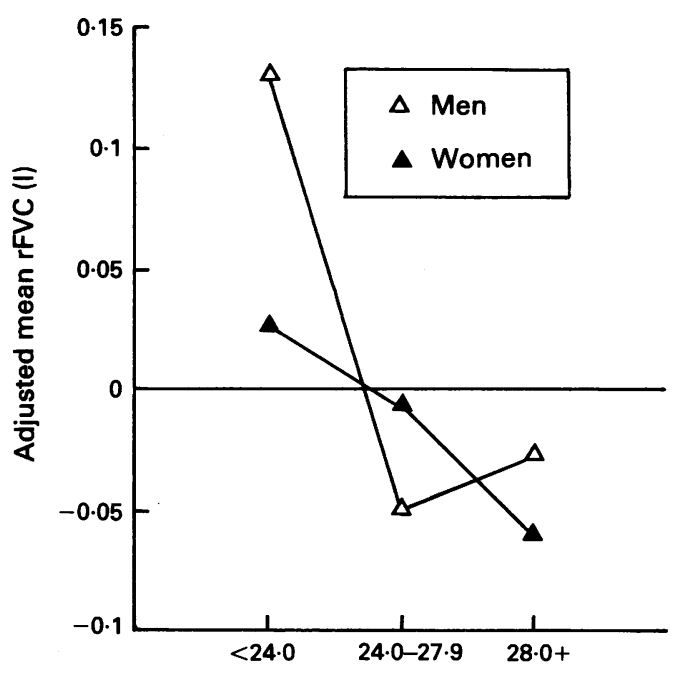

Body mass index at baseline $\left(\mathrm{kg} / \mathrm{m}^{2}\right)$

The data show that weight gain was an important predictor of decline of FVC and $\mathrm{FEV}_{1}$ in both men and women. Average weight gain over the six year period was less in men than in women, 1.3 (SD 4.8) $\mathrm{kg} v 2.7$ (SD 6.4) $\mathrm{kg}(F=10 \cdot 175, \mathrm{p}=0.002)$. The subjects were classified into three groups according to weight gain from 1977 to 1983 $(<1.0 \mathrm{~kg}, 1.0-3.9 \mathrm{~kg}$, and $\geqslant 4.0 \mathrm{~kg})$. Table 3 shows that both mean rFVC and $\mathrm{rFEV}_{1}$ were highest in the $<1.0 \mathrm{~kg}$ group and lowest in the

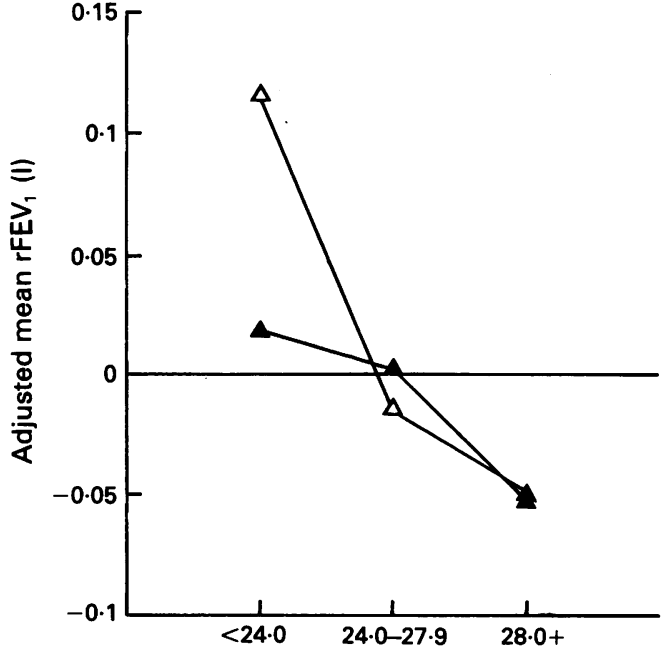

Body mass index at baseline $\left(\mathrm{kg} / \mathrm{m}^{2}\right)$

$\geqslant 4.0 \mathrm{~kg}$ group, and intermediate in the $1.0-3.9 \mathrm{~kg}$ group in both men and women. After adjustment for age, BMI at baseline, and smoking, the $\mathrm{rFVC}$ and $\mathrm{rFEV}_{1}$ were significantly related to weight gain (table 3 )that is, the greater the weight gain, the larger

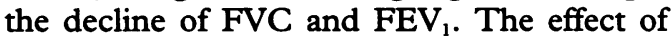
weight gain on decline of FVC and $\mathrm{FEV}_{1}$ was greater in men than in women (table 3, fig 2). The difference in the adjusted mean rFVC between the $<1.0 \mathrm{~kg}$ group and the $\geqslant 4.0 \mathrm{~kg}$

Table 3 Mean (SD) residual pulmonary function test variables by weight gain and gender, crude and adjusted for age, BMI at baseline and smoking (analysis of covariance)

\begin{tabular}{|c|c|c|c|c|c|c|c|}
\hline \multirow[b]{2}{*}{ Weight gain ( $\mathrm{kg}$ ) } & \multirow[b]{2}{*}{$n$} & \multicolumn{2}{|l|}{$r F V C(l)$} & \multicolumn{2}{|l|}{$r F E V_{1}(l)$} & \multicolumn{2}{|l|}{$r M M F R(l / s)$} \\
\hline & & Crude & Adjusted & Crude & Adjusted & Crude & Adjusted \\
\hline \multicolumn{8}{|l|}{ Men } \\
\hline$<1 \cdot 0$ & 121 & $0.109(0.377)$ & 0.122 & $0.093(0.294)$ & $0 \cdot 108$ & $0.098(0.990)$ & 0.153 \\
\hline $1 \cdot 0-3 \cdot 9$ & 101 & $-0.026(0.384)$ & -0.024 & $-0.017(0.316)$ & -0.013 & $-0.080(0.841)$ & -0.081 \\
\hline$\geqslant 4 \cdot 0$ & 94 & $-0.113(0.446)$ & -0.128 & $-0.100(0.352)$ & $-0 \cdot 120$ & $-0.041(0.939)$ & -0.094 \\
\hline$F$ & & $8 \cdot 462$ & $10 \cdot 199$ & $9 \cdot 879$ & $13 \cdot 858$ & $1 \cdot 141$ & $2 \cdot 767$ \\
\hline $\mathbf{p}$ & & $<0.001$ & $<0.001$ & $<0.001$ & $<0.001$ & 0.321 & 0.064 \\
\hline \multicolumn{8}{|l|}{ Women } \\
\hline$<1 \cdot 0$ & 138 & $0.046(0.241)$ & 0.055 & $0.044(0.206)$ & 0.050 & $-0.005(0.575)$ & 0.001 \\
\hline $1 \cdot 0-3 \cdot 9$ & 103 & $-0.003(0.270)$ & -0.001 & $-0.004(0.187)$ & -0.003 & $-0.001(0.601)$ & 0.044 \\
\hline$\geqslant 4 \cdot 0$ & 146 & $-0.042(0.371)$ & -0.055 & $-0.038(0.286)$ & -0.051 & $-0.006(0.713)$ & -0.046 \\
\hline$F$ & & $2 \cdot 964$ & $4 \cdot 964$ & $4 \cdot 320$ & $6 \cdot 887$ & 0.012 & 0.672 \\
\hline $\mathbf{p}$ & & 0.053 & 0.007 & 0.014 & 0.001 & 0.988 & 0.511 \\
\hline
\end{tabular}

For definition of abbreviations see table 2 . 
Figure 2 Relationship between residual pulmonary function measurements and weight gain in men and women gain in men and women baseline, and smoking).

Figure 3 Regression for residual $F V C$ and $F E V_{1}$ as functions of weight gain in men and women.
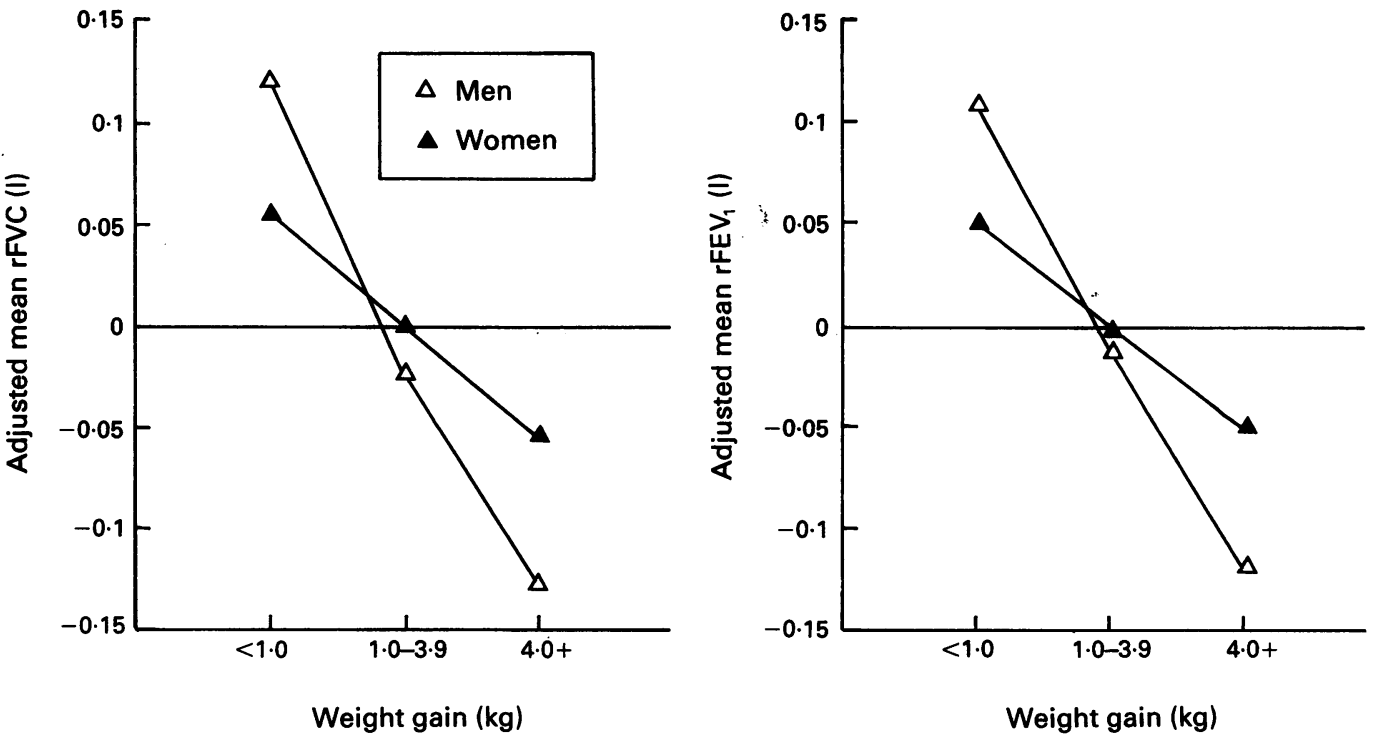

Table 4 Multiple regression analysis of relationship between residual pulmonary function and weight gain and BMI change adjusted for age, BMI at baseline, and smoking.

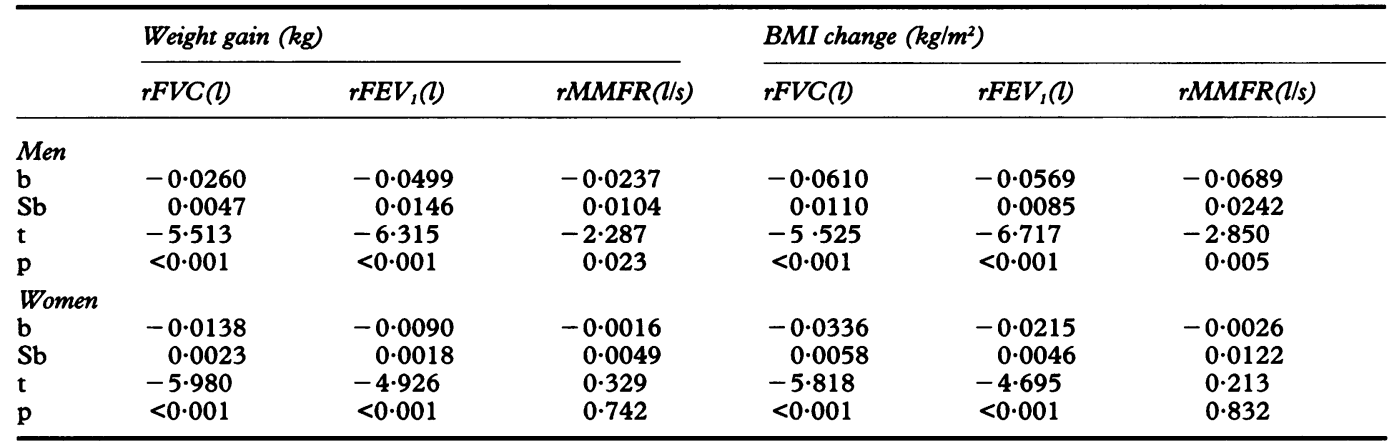

b-partial regression coefficient; $\mathrm{Sb}$-standard error of partial regression coefficient. For definitions of other abbreviations see table 2 .

group was $245 \mathrm{ml}$ in men and $106 \mathrm{ml}$ in women. The difference in the adjusted mean $\mathrm{rFEV}_{1}$ between the two groups was $229 \mathrm{ml}$ in men and $98 \mathrm{ml}$ in women.

Multiple regression analysis shows that weight gain was significantly related to decline of FVC, $F_{1}$, and MMFR in men and to FVC and FEV 1 in women after taking age, BMI at baseline, and smoking into account (table 4). Each kilogram of weight

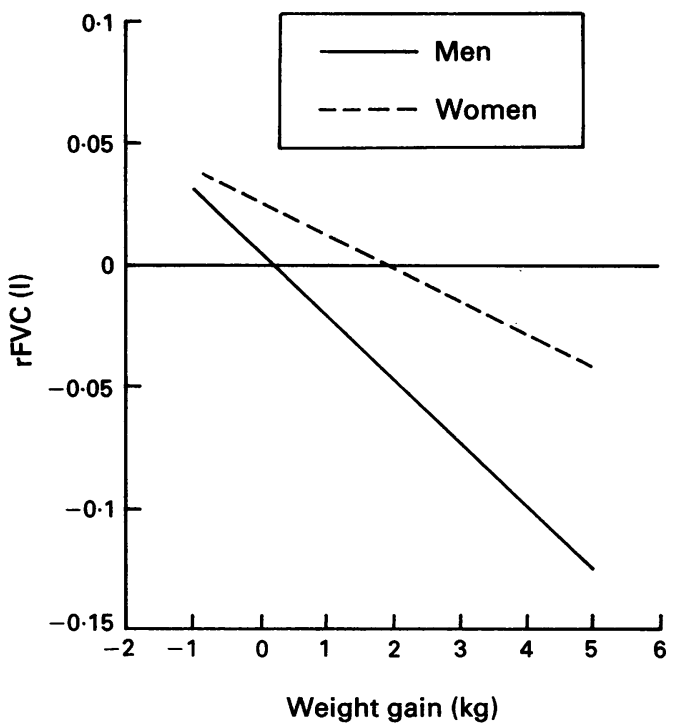

gain from 1977 to 1983 was associated with an average excess loss of $26 \mathrm{ml}$ in FVC, $23 \mathrm{ml}$ in $\mathrm{FEV}_{1}$ and $24 \mathrm{ml} / \mathrm{s}$ in MMFR in men. In women, the excess losses were $14 \mathrm{ml}$ in FVC and $9 \mathrm{ml}$ in $\mathrm{FEV}_{1}$. Table 4 also shows similar results for the relationships between $\mathrm{BMI}$ change over six years and pulmonary function measurements. The regressions for the residual FVC and FEV in both men and women (average age and BMI at baseline and non-

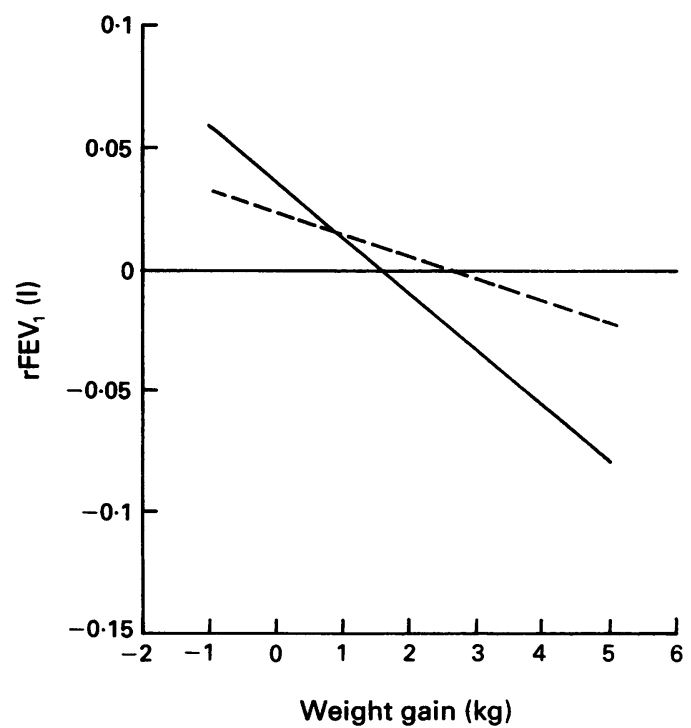


Table 5 Significant test of gender and weight gain and their interaction on residual pulmonary function adjusted for age, BMI at baseline and smoking

\begin{tabular}{|c|c|c|c|c|c|c|}
\hline & \multicolumn{2}{|l|}{$r F V C(l)$} & \multicolumn{2}{|l|}{$r F E V_{1}(l)$} & \multicolumn{2}{|c|}{$r M M F R(l / s)$} \\
\hline & $t$ & $p$ & $t$ & $p$ & $t$ & $p$ \\
\hline $\begin{array}{l}\text { Gender } \\
\text { Weight gain } \\
\text { Gender } \times \text { weight gain }\end{array}$ & $\begin{array}{r}0.358 \\
-4 \cdot 799 \\
2 \cdot 782\end{array}$ & $\begin{array}{r}0.720 \\
<0.001 \\
0.006\end{array}$ & $\begin{array}{r}0.275 \\
-5 \cdot 487 \\
3.543\end{array}$ & $\begin{array}{r}0.783 \\
<0.001 \\
<0.001\end{array}$ & $\begin{array}{r}0.090 \\
-0.785 \\
1.056\end{array}$ & $\begin{array}{l}0.928 \\
0.433 \\
0.291\end{array}$ \\
\hline
\end{tabular}

For definition of abbreviations see table 2 .

smoking state) plotted as a function of weight gain are shown in fig 3.

We used interaction of weight gain with gender to assess whether the gender difference in the relationship between weight gain and pulmonary function was significant. Table 5 shows the results of significance tests after adjustment for age, smoking, and BMI at baseline. The interaction term of weight gain with gender was significantly related to FVC $(t=2.782, p=0.006)$ and $F_{1}(t=$ $3.543, p<0.001)$, suggesting that the relationship between weight gain and pulmonary function was stronger in men than in women.

\section{Discussion}

This study shows that BMI at baseline and subsequent weight gain were significantly related to decline of pulmonary function tests in adults. Compared with BMI at baseline, weight gain was a more prominent predictor of pulmonary function decline, and was significantly related to decline of FVC, $\mathrm{FEV}_{1}$, and MMFR in men and to decline of FVC and $\mathrm{FEV}_{1}$ in women during the six year follow up period. The unit effect of weight gain was larger in men than in women although women gained more weight than men during the study period.

We were aware of, and attempted to adjust for, a number of potential confounding variables that might relate to the effects of body weight on pulmonary function. ${ }^{25}$ The analysis was carried out to detect changes in pulmonary function test variables related to weight gain over a six year period (from 1977 to 1983). It was necessary to control for confounding effects before and during the six years. Stagewise analysis was used to adjust the confounding effects in two stages. Firstly, we used the "residual" analysis technique to remove the effects of body weight and confounding factors that occurred before the study period. We found, for example, that total smoking (pack years) before 1977 was not related to the residual pulmonary function measurements. This type of "residual" analysis also removed the effects of initial pulmonary function measurements on final measurements. Secondly, we used multiple regression analysis to determine the effect of weight gain on the residual pulmonary function measurements after adjustment for the effects of potential confounding factors that occurred during the study period. The effect of weight gain on decline of pulmonary function was found to be independent of smoking and was not confounded by a history of cardiopulmonary disease.

Previous studies have suggested that pulmonary function was decreased at both extremes of weight. ${ }^{14-16}$ In a study of 7123 male air military personnel (3149 under 20 years of age) by Bande and coworkers, ${ }^{15}$ both cross sectional and longitudinal analyses showed a similar relationship between weight and pulmonary function in non-smokers; in smokers, this effect was less pronounced. Dockery and coworkers ${ }^{16}$ reported lower lung function than expected in subjects weighing more than $15 \mathrm{~kg}$ above or below the expected mean weight for their height and gender in a study of 2454 non-smoking adults aged 2574 years in six American cities. In contrast to our study, these results were mainly obtained from non-smoking healthy ${ }^{14-16}$ or younger ${ }^{14,15}$ populations. If the initial increase in pulmonary function with increasing weight is considered a "muscularity effect" and the decrease with further increasing weight an "obesity effect", 14 weight in our population, which ranged from 25 to 59 years and included both healthy and "unhealthy" subjects, would have more "obesity effect" than "muscularity effect." In addition, weight is closely correlated with body size and BMI is an indicator of obesity. Our results showing decreasing residuals of pulmonary function with increasing BMI at baseline are not in conflict with the results of these studies.

Weight gain related to decline of FVC has been documented in previous studies. In a longitudinal study of 592 men aged 25-74 years living in a rural unpolluted area, Dontas and colleagues ${ }^{18}$ found that in the subjects with $\mathrm{BMI} \geqslant 21 \mathrm{~kg} / \mathrm{m}^{2}$ at baseline, the greater the increase of the BMI at the 10 year follow up, the greater the loss of FVC. The change in BMI, however, was not found to be related to decline of $\mathrm{FEV}_{0.75}$. In another longitudinal study of 1396 men aged 21-81 years at baseline, weight gain was significantly associated with loss of FVC. ${ }^{19}$ Our data show that weight gain not only affected FVC, but also $\mathrm{FEV}_{1}$ and MMFR in men and $\mathrm{FEV}_{1}$ in women.

Previous studies in obese persons have documented decreased functional residual capacity and expiratory reserve volume. ${ }^{3-13}$ The findings for airway function in obesity, however, have been conflicting. Rubinstein and coworkers ${ }^{13}$ compared 103 obese nonsmokers with 109 non-smoking controls matched for gender, age, and height and found significantly reduced $\mathrm{FEV}_{1}$ and maximal expiratory flow rates at $50 \%$ and $75 \%$ of exhaled vital capacity in obese men and reduced $\mathrm{FEV}_{1}$ in obese women. In a cross sectional study of steelworkers (105 current smokers, 54 non-smokers and 51 ex-smokers) aged 45-55 years, however, Nemery and coworkers found that lower values of $\mathrm{BMI}$ were closely correlated with lower $\mathrm{FEV}_{1} / \mathrm{VC}$ in current smokers, but not in non-smokers and ex-smokers. ${ }^{20}$ They suggested that impaired pulmonary function might cause the affected smokers to lose weight, or reflect the effect of cigarette smoking on both the 
respiratory tract and metabolism. The subjects in their study, however, represent a particular group of steelworkers rather than a general population. Other studies show no significant relationship between obesity and airways function. ${ }^{126-28}$ The reasons for this controversy could include methodological limitations, particularly in sample selection, sample size, and confounder controlling, and may have contributed to the apparent lack of significance in the relationship between obesity and airways function. ${ }^{13}$

Our data show that weight gain was linearly related to decline of lung function test variables (FVC, FEV ${ }_{1}$, and MMFR in men and FVC and $\mathrm{FEV}_{1}$ in women). BMI is frequently used as a surrogate measure for obesity in epidemiological studies. In this longitudinal analysis, height was almost constant during the study period and BMI change from 1977 to 1983 showed a similar relationship to pulmonary function decline. There was no evidence in our study of any apparent threshold in decline of pulmonary function with increasing weight gain. The risk was continuously distributed.

The effect of weight gain on pulmonary function decline was larger in men than in women. These findings were consistent with those reported by Rubinstein and coworkers ${ }^{13}$ who found that obese men had reduced forced expiratory flow rates at low lung volumes, whereas obese women did not.

The progressive reduction in expired flow rates with increasing age, as reflected by $\mathrm{FEV}_{1}$, has been thought to be related to progressive loss of the elastic recoil properties of the lung with age. ${ }^{29}$ When longitudinal studies of lung function became available, there appeared to be a more modest loss of lung function with age ${ }^{30}$ leading to speculation that apparent losses from cross sectional studies could reflect intergenerational differences. Our study indicates that weight gain may be a determinant of loss of lung function. These findings suggest that the influence of weight gain on decline of pulmonary function is independent of the possible effect of loss of elastic recoil with increasing age.

Whatever the aetiology, weight gain is likely to be a significant risk factor in its decline of pulmonary function in adults. These findings raise the possibility that weight gain may be one of the principal determinants of reduction in lung function, and that the relationship may be modified by gender.

$\mathrm{Y}$ Chen is partly supported by the Saskatchewan Health Research Board and J A Dosman is a scholar of Health and Welfare Canada.

1 US Department of Health and Human Services. The health benefits of smoking cessation: a report of the surgeon health benefits of smoking cessation: a report of the surgeon
general. DHHS Publication No. (CDC) 90-8416. general. DHHS Publication No. (CDC) 90-8416.
Washington, DC: Government Printing Office, 1990: Washin

2 National Institutes of Health Consensus Development
Conference Statement. Health implications of obesity. Ann Intern Med 1985;103:1073-7.

3 Bedell GN, Wilson WR, Seebohm RM. Pulmonary function in obese persons. $₹$ Clin Invest 1958;37:1049-60.

4 Naimark A, Cherniack RM. Compliance of the respiratory system and its components in health and obesity. $\mathcal{F} A p p l$ Physiol 1960;15:377-82.

5 Gilbert R, Sipple JH, Auchincloss JH Jr. Respiratory control and work of breathing in obese subjects. F Appl Physiol 1961;16:21-6.

6 Alexander JK, Amad KH, Cole VW. Observations on some clinical features of extreme obesity, with particular reference to cardiorespiratory effects. $\mathrm{Am} \mathcal{F} \mathrm{Med}$ 1962;32:512-14.

7 Cullen JH, Formel PF. The respiratory defects in extreme obesity. Am f Med 1962;32:525-31.

8 Barrera F, Reidenberg MM, Winters WL. Pulmonary function in the obese patient. Am $f$ Med Sci 1967; 254:785-96.

9 Emirgil C, Sobol BJ. The effects of weight reduction on pulmonary function and the sensitivity of the respiratory centre in obesity. Am Rev Respir Dis 1973;108:831-42.

10 Luce JM. Respiratory complications of obesity. Chest 1980;78:626-31.

11 Suratt PM, Wilhoit SC, Hsiao HS, Atkinson RL, Rochester DF. Compliance of chest wall in obese subjects. F Appl Physiol 1984;57:403-7.

12 Ray CS, Sue DY, Bray G, Hansen JE, Wasserman K. Effects of obesity on respiratory function. Am Rev Respir Dis 1983;128:501-6.

13 Rubinstein I, Zamel N, DuBarry L, Hoffstein V. Airflow limitation in morbidly obese, non-smoking men. Ann Intern Med 1990;112:828-32.

14 Schoenberg JB, Beck GJ, Bouhuys A. Growth and decay pulmonary function in healthy blacks and whites. Respir Physiol 1978;33:367-93.

15 Bande J, Clement J, Van de Woestijne KP. The influence of smoking habits and body weight on vital capacity and $\mathrm{FEV}_{1}$ in male air force personnel: a longitudinal and cross-sectional analysis. Am Rev Respir Dis 1980; 122:781-90.

16 Dockery DW, Ware JH, Ferris BG Jr, Glicksberg DS, Fay ME, Spiro III A, et al Distribution of forced expiratory volume in one second and forced vital capacity in healthy, white, adult never-smokers in six US cities. $\mathrm{Am}$ Rev Respir Dis 1985;131:511-20.

17 Heederik D, Miller BG. Weak associations in occupational epidemiology: adjustment for exposure estimation error. Int $\mathcal{F}$ Epidemiol 1988;17:970-4.

18 Dontas AS, Jacobs DR Jr, Corcondilas A, Keys A Hannan P. Longitudinal versus cross-sectional vital capacity changes and affecting factors. $f$ Gerontol 1984;39:430-8.

19 Borkan GA, Sparrow D, Wisniewski C, Vokonas PS. Body weight and coronary disease risk: patterns of risk factor change associated with long-term weight change. The Normative aging study. Am $\mathcal{f}$ Epidemiol 1986; 124:410-9.

20 Nemery B, Moavero NE, Brasseur L, Stanescu DC Smoking, lung function, and body weight. $B M \mathcal{F}$ 1983;286:249-51.

21 Chen Y, Horne SL, Dosman JA. Increased susceptibility to lung dysfunction in female smokers. Am Rev Respir Dis 1991;143:1224-30.

22 Chen Y, Horne SL, McDuffie HH, Dosman JA Combined effect of grain farming and smoking on lung function and the prevalence of chronic bronchitis. Int $\mathcal{F}$ Epidemiol 1991;20:416-23.

23 Esrey SA, Casella G, Habicht J-P. The use of residuals for longitudinal data analysis: the example of child growth Am F Epidemiol 1990;131:365-72.

24 SPSS Inc. SPSS-X introductory statistics guide. Chicago: SPSS Inc., 1988.

25 Stallones RA. Epidemiologic studies of obesity. Ann Intern Med 1985;103:1003-5.

26 Kollias J, Boileau RA, Bartlett HL, Buskirk ER. Pulmonary function and physical conditioning in lean and obese subjects. Arch Environ Health 1972; 25:146-50.

27 Crapo RO, Kelly TM, Elliott CG, Jones SB. Spirometry as a preoperative screening test in morbidly obese patients. Surgery 1986;99:763-8.

28 Thomas PS, Cowen ER, Hulands G, Milledge JS Respiratory function in the morbidly obese before and after weight loss. Thorax 1989;44:382-6.

29 Bode FR, Dosman JA, Martin RR, Ghezzo H, Macklem PT. Age and sex differences in lung elasticity, and in closing capacity in non-smokers. I Appl Physiol 1976;41:129-35.

30 Ware JH, Dockery WD, Louis TA, Xu X, Ferris BG Jr, Speizer FE. Longitudinal and cross-sectional estimates of pulmonary function decline in never-smoking adults. Am $\mathcal{F}$ Epidemiol 1990;132:685-700. 